\title{
Congenital Atresia of the Larynx in Association with Prune Belly Syndrome
}

\author{
Maj A J Lyon \\ MA, MRCP, RAMC \\ British Military Hospital, Rinteln
}

SUMMARY: A case of congenital atresia of the larynx in association with the Prune Belly Syndrome ofs reported. Some aspects of the aetiology and management of congenital atresia of the larynx are reviewcy.

\section{Introduction}

I wish to report a case of congenital atresia of the larynx in association with absence of abdominal muscles. This is the first case reported of this anomaly in a child with "Prune Belly" Syndrome.

\section{Case Report}

A $1300 \mathrm{~g}$, male infant was born by cmergency Caesarian Section to a 22 year old Primigravid woman. The labour was spontaneous, with brecch presentation, at 31 wecks gestation. Ritodrine infusion had failed to stop the labour and foetal heart monitoring for several hours before operation was normal.

At delivery. the haby made gasping mozements but the lungs did not expand. Intubation was impossible because of a solid bar of tissue across the larynx. An airway was not established and the baby died after 10 minutes.

Several abnormal features were noted as shown in Figure 1. These included low set dysplastic ears and a soft, distended abdomen. Post mortem examination confirmed layngeal atresia. The fusion appeared to be below the true vocal cords. There was a small pinhole opening through the posterior part of the atretic area. The lungs were hypoplastic but the base of the right lung was partly expanded.

The brain was smooth with no gyral pattern.

No muscle was found in the abdominal wall. There was only one umbilical artery but no obvious siructural abnormality of the renal tract.

Chromosome analysis of blood taken just before death revealed a normal male karyotype. There was no detectable specific IgM for rubella, toxoplasma, cytomegalovirus or herpes virus.

\section{Discussion}

Congenital atresia of the larynx is generally regarded as being a rare anomaly and in a substantial proportion of cases it is associated with other potentially fatal abnormalities.

Smith and Baine ${ }^{1}$ report nine cases of atresia of the larynx. They suggest that the anomaly comprise a spectrum of malformation which include the com. genital webs between the vocal cords.

Three types of atresia are distinguished: Type one in which the supraglottic and infraglottic parts the larynx are atretic; Type two in which tis airesia, as in this case, is infraglottic; and $B$ de

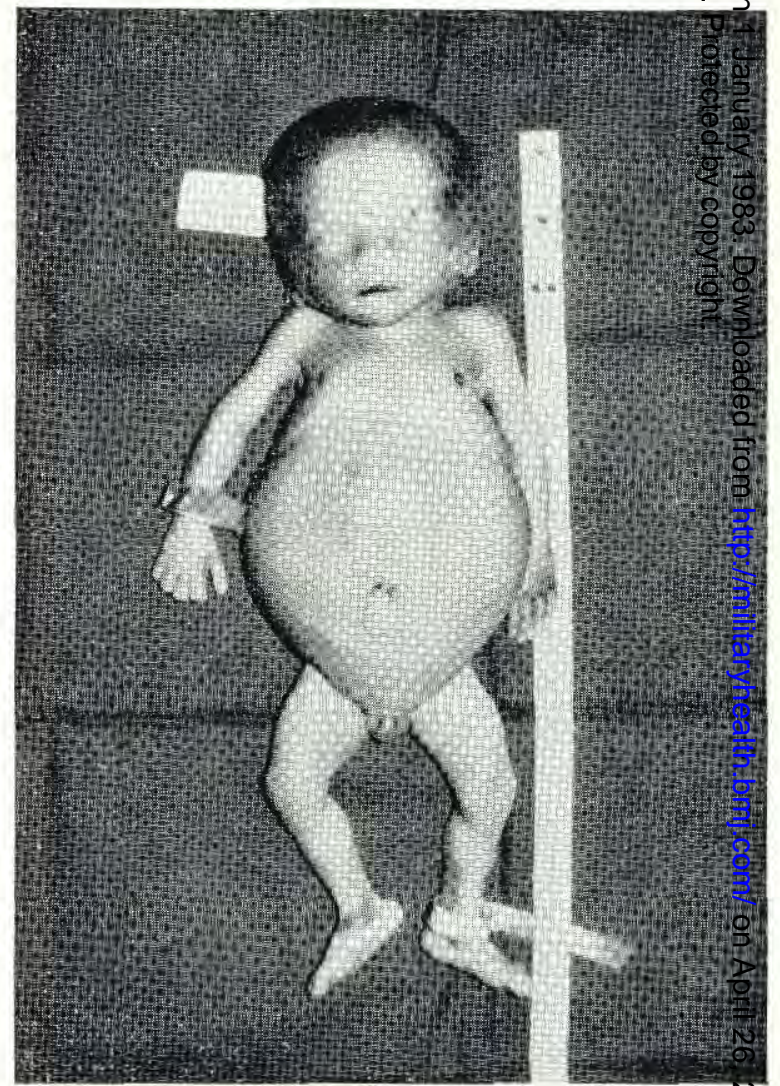

Fig. 1 Showing abnormal features in the male infant. 
three in which it is glottic. In all cases there is a persistence of a posterior pinhole opening in the atretic area.

Walender ${ }^{2}, \quad 3$ describes the formation of the laynx from a solid epithelial outgrowth from the pharynx. His hypothesis is partly speculative and based on the embryology of the rat larynx, but, unlike the more generally favoured view of the development of the larynx, can explain the different types of congenital atresia. In particular he describes the formation of a posterior opening, the pharyngotracheal duct which normally merges with the cavity of the definitive vestibule. No aetiological factors have been reported in association with laryngeal atresia or "Prune Belly."

The larynx first appears in the fetus at 25-28 days gestation and its cavity is closed until about the third month. The mesodermal segmentation ultimately responsible for the formation of the abdominal musculature starts at approximately 23 days. A defect occurring between 20-30 days could be responsible for both abnormalities. No possible cause was found in this case.

Hereditary influences play a part in congenital laryngeal atresia and several members of the same family have been described with varying degrees of atresia $^{4}$.

If an airway can be established at birth, the prognosis for the child often depends on the severity of any associated congenital abnormalities Tracheostomy may be needed in the initial manages ment, but, in the long term, correction should now be undertaken too early as this may cause seriou disturbances in the growth of the larnyx and affects final voice production. The larynx continues to develop after birth and early reconstructive surgery may affect the growth centres of the cartilaginou $\overrightarrow{\bar{s}}$ structures. The best results in laryngeal atresiof appear to be in cases were definitive surgery can be delayed as long as possible ${ }^{4}$.

Congenital webs are usually isolated anomalies an $\overline{\text { क }}$ present less of a management problem. There is $\frac{\rho}{4}$ case for treating them early, as persistence of the web can cause a disturbance in the developmen $\vec{D}$ of the laryn $\mathrm{x}^{4}$, probably as a result of the increased effort needed for voice production.

\section{REFERENCES}

1 SMITH I I, BAIN A D. Congenital Atresia of the Larynx. Ann Otol Rhinol Laryngol 1965; 74: 338-349.

2 WALENDER A. Prenatal Development of the thelial Primordium of the Larynx in Rats. Af $t$. Anat (Basel) 1950; 10: supp 2.

3 WALENDER A. The Mechanism of Origin of Congenital Malformations of the Larynx. Acta $\bar{a}_{0}$ Larnyg 1955; 45: 246.

4 BAKER D C, SAVETSKy L. Congenital Partial Atr ${ }^{-4 i}$ of the Larynx. Laryngoscope 1966; 76: 616-62\% 